\title{
The Phillips and Beveridge Curves Revisited *
}

\author{
A. Chéron $†$ F. Langot $\ddagger$
}

February 1999

$n^{\circ} 9905$

*Corresponding author: A. Chéron, EUREQUA, Université de Paris I, 106-112 Bld de l'Hôpital, 75013 Paris, France. Tel: 01554342 11. We would like to thank P. Beaudry, J.P. Benassy, P. Cahuc, F. Collard, P. Fève, J.O. Hairault, P.Y. Hénin, T. Kehoe, H. Kempf and F. Portier for helpful comments. We thank also the participants at the May 1998 T2M Congress in Marseille, July 1998 III Workshop on Dynamic Macroeconomic in Vigo, September 1998 E.E.A. Congress in Berlin, E.E.A. Summer School in Paris, CEPREMAP and EUREQUA seminars. All remaining errors and insufficiencies are our own.

†EUREQUA (Université de Paris I) and GAINS (Université du Maine) - acheron@univparis1.fr

‡CEPREMAP and GAINS (Université du Maine) - flangot@univ-lemans.fr 


\title{
The Phillips and Beveridge Curves Revisited
}

\begin{abstract}
This paper studies the cyclical labor market properties of a model which aims to account for the Phillips and Beveridge curves. Monopolistic competition and sticky prices on the goods market are introduced in a labor market search model disturbed by both technological and money supply shocks. We explain the specific propagation mechanisms on the labor market related to money supply shocks and show that they help to understand aggregate labor market dynamics.
\end{abstract}

Keywords: Nominal and Real Rigidities, Unemployment, Business Cycle

\section{Les courbes de Phillips et de Beveridge: une reformulation}

\section{Résumé}

Ce papier étudie les propriétés cycliques d'un modèle qui donne des fondements aux courbes de Phillips et de Beveridge. Sur le marché des biens, il fait l'hypothèse de concurrence monopolistique et de rigidités de prix. Sur le marché du travail, l'emploi est déterminé par un processus d'appariement et le salaire par des négociations salariales. Nous expliquons les mécanismes de propagation sur le marché du travail spécifiques aux chocs d'offre de monnaie et montrons qu'ils sont quantitativement pertinents.

Mots clés: Rigidités Nominales et Réelles, Chômage, Cycle

JEL Classification: E24, E31, E32 


\section{Introduction}

Beyond the dynamics of labor productivity, employment, hours per worker and the real wage, US labor market stylized facts are characterized by negative correlations between inflation and unemployment and between vacancies and unemployment, the so-called Phillips and Beveridge curves. The seminal Phelps and al. [1970]'s work emphasizes the role of labor and goods markets frictions in generating these empirical regularities. As already suggested by Friedman [1968], the existence of real and nominal rigidities in an economy disturbed both by technological and monetary shocks can give some foundations to these stylized facts.

For this purpose, we slightly modify the augmented Real Business Cycle with labor market search proposed by Andolfatto [1996]: (i) real balances yield some utility, (ii) there are monopolistic competition and sticky prices on the goods market, and (iii) the economy is disturbed both by technological and money supply shocks. Despite the assumption of an exogenous quit rate, Andolfatto [1996] and Merz [1995] show that the matching process is sufficient to reproduce the observed negative correlation between vacancies and unemployment ${ }^{1}$. It is clear that models with endogenous job destruction rate allow to understand both firings and hirings (see Cole and Rogerson [1996] and Den Haan, Ramey and Watson [1997]). However, this assumption does not improve the reproduction of aggregate labor market dynamics ${ }^{2}$.

This paper demonstrates that our small structural model with non-neutrality of money supply shocks allows to account also for the Phillips curve. In addition, it implies a significant improvement of the model's fit along the stylized facts reported in Andolfatto [1996]: the dynamics of hours per worker, labor's share $^{3}$ and labor productivity are better reproduced. The non-neutrality of money is introduced via nominal rigidities, as in Hairault and Portier [1993] and Ireland [1997] ${ }^{4}$. Indeed, Cooley and Hansen [1997] have shown that dynamic general equilibrium models with Cash-in-advance or unanticipated

\footnotetext{
${ }^{1}$ Fève and Langot [1996] show also that this type of RBC model with search on the labor market is a good way to reproduce European labor market stylized facts.

${ }^{2}$ Moreover, the Andolfatto [1996] model succeeds to propagate productivity shocks in the manner suggested by the observed persistence in actual output growth rate (the Cogley and Nason [1995] test).

${ }^{3}$ This statistic is crucial since it gives an implicit indicator, (i) of the way that the real wage dynamic differs from the one of the labor productivity, and (ii) of the profit's share dynamic: if the model is capable of reproducing the labor's share dynamic, so does for the profit's share (measured in accordance with the model).

${ }^{4}$ The introduction of sticky prices requires to derive the optimal price decision rule for each firm. This is done following the way suggested by Rotemberg and Woodford [1995].
} 
inflation effect à la Lucas do not imply significant or relevant propagation mechanisms of monetary shocks. Moreover, as it is shown in the Christiano, Eichenbaum and Evans [1997]'s empirical investigation, the real wage decreases following a negative money supply shock: the staggered nominal contracts assumption is in contradiction with this result. Finally, the business cycle model of Cooley and Quadrini [1998], where the non-neutrality of money comes from a limited participation assumption, fails to reproduce the volatility of employment for a reasonable guess of structural parameters, whereas Andolfatto succeeds $s^{5}$.

The quantitative properties of the model are evaluated following the methodology proposed by Kydland and Prescott [1982]. Parameters of the model are chosen according to US data, and simulation experiments are conducted. Our evaluation strategy is the following. We study three versions of our model: (i) the first version corresponds to the model of Andolfatto [1996] augmented by a money demand behavior (model M1), (ii) the second one corresponds to the same model with price adjustment costs and monopolistic competition on the goods market (model M2), and (iii) the final one includes money supply disturbances (model M3).

The plan of the paper is as follows. Section 1 describes the monetary model with labor market search. Calibration is presented in Section 2. Impulse response functions and simulations results are discussed in Section 3. Section 4 offers some concluding remarks.

\section{The Model}

First, the matching process is described. Then we present the household and firms' program. Finally, the labor contract is derived.

\subsection{Trade on the Labor Market}

Following Pissarides [1990], we assume that trade on the labor market is a costly and uncoordinated economic activity. We suppose a complete specialization in either trade or production ${ }^{6}$ : only unemployed workers and unfilled jobs are engaged in the search process. The size of the population is normalized to one. Let $N_{t}$ denote the number of exiting jobs that are at the beginning of period $t, U_{t}=1-N_{t}$ is the measure of unemployment rate. As

\footnotetext{
'In particular, with the Andolfatto [1996] calibration of the workers' bargaining power, the model of Cooley and Quadrini [1998] implies a volatility of employment close to zero.

${ }^{6}$ See Mortensen [1994] for a quantitative evaluation of the "on-the-job search" assumption.
} 
in Andolfatto [1996], unemployed workers are assumed to search passively; denoting $e$ the search effort per worker looking for a job, $e U_{t}$ is the aggregate search effort. $V_{t}$ denotes the total number of vacancies which incurs a flow cost equal to $\omega$. The rate $H_{t}$ at which new job matches form is governed by an aggregate-matching technology :

$$
H_{t}=h V_{t}^{\psi}\left(e U_{t}\right)^{1-\psi}
$$

This function satisfies the usual properties of the neo-classical production function, including constant returns to scale $e^{7}$. The law of motion for aggregate employment is defined by:

$$
N_{t+1}=(1-s) N_{t}+H_{t}
$$

In equilibrium, unemployment persists because in each and every period some existing jobs disappear at a constant rate $s$, resulting in a flow of new unemployed workers.

\subsection{The Household's behavior}

Each household participates to the trade on the labor market, supplies a flexible number of hours and consumes a basket of all goods produced in the economy. We assume that real money balances yield some utility.

We denote $C_{t}$ the consumption for a representative household; it is a C.E.S. basket of the different goods produced in the economy:

$$
C_{t}=\left(\int_{0}^{1} C_{j, t}^{\frac{1}{1+\gamma}} d j\right)^{1+\gamma}
$$

where $\frac{1+\gamma}{\gamma}$ is the elasticity of substitution between the different goods. The optimal composition of this basket is derived from a static problem. For a given level of the consumption index $C_{t}$, the household maximizes this index by choosing $C_{j, t}$ for all $j$, taking price $P_{j, t}$ as given. The solution of this program gives the demand of the household to the firm $j$ :

$$
C_{j, t}=\left(\frac{P_{j, t}}{P_{t}}\right)^{-\frac{1+\gamma}{\gamma}} C_{t} \text { with } P_{t}=\left(\int_{0}^{1} P_{j, t}^{-\frac{1}{\gamma}} d j\right)^{-\gamma}
$$

The random matchings and separations induce different employment histories among households and consequently introduce an heterogeneity in the

\footnotetext{
${ }^{7}$ Cooley and Quadrini [1998] do the non-standard assumption of decreasing returns to scale.
} 
wealth. However, assuming perfect insurance markets (as in Andolfatto [1996] and Den Haan et al. [1997]), the optimal household's behavior can be defined as a problem where ex-post heterogeneity on the labor market does not matter: risk-averse households insure themselves fully against the labor market income's heterogeneity.

Let $M_{t} / P_{t}$ and $h_{j, t}$ denote respectively real balances and the hours per worker, preferences correspond to those retained in Hairault and Portier [1993]. The dynamic program of the household can be defined in the following recursive way ${ }^{8}$ :

$\mathcal{V}\left(\chi_{t}\right)=\max _{\mathcal{C}_{t}}\left\{\log \left[C_{t}^{\frac{\sigma-1}{\sigma}}+\gamma_{3}\left(\frac{M_{t}}{P_{t}}\right)^{\frac{\sigma-1}{\sigma}}\right]^{\frac{\sigma}{\sigma-1}}+N_{t} \Gamma_{t}^{n}+\left(1-N_{t}\right) \Gamma^{u}+\beta E_{t} \mathcal{V}\left(\chi_{t+1}\right)\right\}$

subject to the constraints:

$$
\begin{aligned}
C_{t}+\frac{M_{t+1}}{P_{t}} & =\Pi_{t}+\frac{M_{t}}{P_{t}}+\frac{L S_{t}}{P_{t}}+N_{t} w_{j, t} h_{j, t} \\
N_{t+1} & =(1-s) N_{t}+\Upsilon_{t}\left(1-N_{t}\right)
\end{aligned}
$$

where $\Gamma_{t}^{n}=\gamma_{1} \frac{\left(1-h_{j, t}\right)^{1-\eta}}{1-\eta}$. $\Gamma^{u}$ is the constant value of leisure in unemployed state and $\sigma$ is the constant elasticity of substitution between the consumption and real balances. $w_{j, t}, L S_{t}$ and $N_{t}$ denote respectively the real wage, the monetary lump-sum transfers and the probability for the representative household to be employed. $\Upsilon_{t}=\frac{H_{t}}{U_{t}}$ is the exogenous probability for an unemployed worker to become employed. $\Pi_{t}$ corresponds to the dividends distributed by firms, since the latter are owned by households.

From this dynamic program, we deduce the money demand behavior that characterizes the liquidity effect:

$$
\beta E_{t}\left\{\frac{P_{t}}{P_{t+1}}\left(\lambda_{t+1}\left[\left(1+r_{t+1}\right) \frac{P_{t+1}}{P_{t}}-1\right]-\frac{\gamma_{3}\left(\frac{M_{t+1}}{P_{t+1}}\right)^{-\frac{1}{\sigma}}}{C_{t+1}^{\frac{\sigma-1}{\sigma}}+\gamma_{3}\left(\frac{M_{t+1}}{P_{t+1}}\right)^{\frac{\sigma-1}{\sigma}}}\right)\right\}=0
$$

where the real interest rate is $r_{t+1}=\frac{\lambda_{t}}{\beta \lambda_{t+1}}-1$ and $\lambda_{t}$ denotes the marginal value of the wealth. It means that the anticipated marginal utility of real

\footnotetext{
${ }^{8} \mathrm{We}$ define the vectors of control variables $\mathcal{C}_{t}=\left\{C_{t}, \frac{M_{t+1}}{P_{t}}\right\}$ and state variables $\chi_{t}=$ $\left\{M_{t}, \Pi_{t}, w_{j, t}, P_{t}, A_{t}, g_{t}\right\}$, where $A_{t}$ and $g_{t}$ are respectively the aggregate technological and money supply shocks.
} 
balances equals its anticipated opportunity cost (it expresses the arbitration between real balances and the firms' ownership). This relation shows that the nominal interest rate is a decreasing function of the amount of real balances: it refers to the liquidity effect.

Concerning the money supply rule, we assume that its law of motion is given by:

$$
M_{t+1}^{s}=M_{t}^{s} g_{t}
$$

where the stochastic process of the monetary growth $\left(g_{t}\right)$ follows an $A R(1)$ process:

$$
\log g_{t}=\rho_{g} \log g_{t-1}+\left(1-\rho_{g}\right) \log \bar{g}+\epsilon_{g, t}
$$

where $\left|\rho_{g}\right|<1$ and $\epsilon_{g, t} \leadsto \mathcal{N}\left(0, \sigma_{g}\right)$.

\subsection{Firms' Behavior}

Each firm has a monopoly power on its market. Assuming an important number of firms (a continuum on the interval $[0,1]$ ) ensures that each firm does not take into account that its behavior affects aggregate variables. So, firms charge a price taking the demand function they face into account, but aggregate demand and aggregate price level as given. All firms have access to the same technology:

$$
Y_{j, t}=A_{t}\left(h_{j, t} N_{j, t}\right)^{\alpha} K_{j, t}^{1-\alpha}-F
$$

where $Y_{j, t}, h_{j, t}, N_{j, t}$ and $K_{j, t}$ respectively denote the output, the hours per worker, the employment, the physical capital stock in the firm $j . F>0$ is a fixed cost so that $\frac{Y_{j, t}+F}{Y_{j, t}}$ is the index of increasing returns (see Rotemberg and Woodford [1995]). $A_{t}$ denotes the aggregate technological shock, which follows the stochastic process:

$$
\log A_{t}=\rho_{A} \log A_{t-1}+\left(1-\rho_{A}\right) \log \bar{A}+\epsilon_{A, t}
$$

where $\left|\rho_{A}\right|<1$ and $\epsilon_{A, t} \leadsto \mathcal{N}\left(0, \sigma_{A}\right)$. We suppose that any change in prices is costly for the firm. Following Rotemberg [1982], Hairault and Portier [1993] and Ireland [1997], the price adjustment costs are assumed to be quadratic:

$$
\mathcal{C A}_{j, t}=\frac{\phi}{2}\left(\frac{P_{j, t}}{P_{j, t-1}}-1\right)^{2}
$$

As suggested by Rotemberg [1982], these costs are of two types. First, there is a fixed cost due to the physical cost of changing prices; this cost is still 
available at steady state, as long as there is a constant price modification. Second, the negative effect of price changes on the reputation of firms is also costly, and increases with the percentage of price changes: the reputation of firm is presumably more affected by large changes in price than by small changes. Let $I_{j, t}$ and $Y_{j, t}^{d}$ denote the investment and the total demand addressed to the firm $j$. The problem of each firm is to maximize the expectation of the discounted sum of its real profit flow with respect to $\mathcal{C}_{j, t}$; it can be written in the following recursive way ${ }^{9}$ :

$\mathcal{W}\left(\chi_{j, t}\right)=\max _{\mathcal{C}_{j, t}}\left\{\frac{P_{j, t}}{P_{t}} Y_{j, t}-w_{j, t} h_{j, t} N_{j, t}-I_{j, t}-\mathcal{C} \mathcal{A}_{j, t}-\omega V_{j, t}+\beta E_{t}\left[\frac{\lambda_{t+1}}{\lambda_{t}} \mathcal{W}\left(\chi_{j, t+1}\right)\right]\right\}$

subject to the following constraints:

$$
\begin{aligned}
K_{j, t+1} & =(1-\delta) K_{j, t}+I_{j, t} \\
N_{j, t+1} & =(1-s) N_{j, t}+\Theta_{t} V_{j, t} \\
Y_{j, t} & \leq Y_{j, t}^{d}
\end{aligned}
$$

where $\delta$ is the depreciation rate of capital. $\Theta_{t}=\frac{H_{t}}{V_{t}}$ is the exogenous probability for each firm that a vacant position becomes a filled position. Although a firm controls employment by opening new jobs, the rate at which job vacancies are filled is exogenous for each firm. To simplify the computation of the demand function addressed to the firm $j$, we assume that investment, vacancies and adjustment costs index have the same structure as the consumption one (these costs are payed via the purchase of the different goods produced in the economy $)^{10}$. Let denote $Y_{t}^{d}=\int_{0}^{1} C_{j, t} d j+\int_{0}^{1}\left(I_{j, t}+V_{j, t}+\mathcal{C A}_{j, t}\right) d j$, the total demand addressed to the firm $j$ is then given by:

$$
Y_{j, t}^{d}=\left(\frac{P_{j, t}}{P_{t}}\right)^{-\frac{1+\gamma}{\gamma}} Y_{t}^{d}
$$

The appendix A presents the firm's decision rules.

\footnotetext{
${ }^{9}$ We define the vectors of control variables $\mathcal{C}_{j, t}=\left\{V_{j, t}, I_{j, t}, P_{j, t}\right\}$ and state variables $\chi_{j, t}=\left\{K_{j, t}, N_{j, t}, w_{j, t}, P_{t}, A_{t}, g_{t}\right\}$.

${ }^{10}$ For $Z=I, V, \mathcal{C A}$ we define:

$$
Z_{j^{\prime}, j, t}=\left(\frac{P_{j, t}}{P_{t}}\right)^{-\frac{1+\gamma}{\gamma}} Z_{j^{\prime}, t}
$$
}




\subsection{The Labor Contract}

The labor contract, stipulating the real wage and the number of hours per worker, is bargained in each and every period between firms and employed workers. Following Pissarides [1990], this bargaining process is given by the solution of the Nash criterion.

The marginal value of a match for the representative household is given by:

$$
\frac{\partial \mathcal{V}\left(\chi_{t}\right)}{\partial N_{t}}=\Gamma_{t}^{n}-\Gamma^{u}+\lambda_{t} w_{j, t} h_{j, t}+\left(1-s-\frac{H_{t}}{U_{t}}\right) \beta E_{t}\left[\frac{\partial \mathcal{V}\left(\chi_{t+1}\right)}{\partial N_{t+1}}\right]
$$

Symmetrically, for firm $j$ this value is given by:

$$
\frac{\partial \mathcal{W}\left(\chi_{j, t}\right)}{\partial N_{j, t}}=\alpha\left(\frac{P_{j, t}}{P_{t}}-\nu_{j, t}\right)\left(\frac{Y_{j, t}+F}{N_{j, t}}\right)-w_{j, t} h_{j, t}+(1-s) \beta E_{t}\left[\frac{\lambda_{t+1}}{\lambda_{t}} \frac{\partial \mathcal{W}\left(\chi_{j, t+1}\right)}{\partial N_{j, t+1}}\right]
$$

Letting $0<\xi<1$ denote the firm's share of the total surplus of a job match, measured in units of goods, from the Nash bargaining criterion we derive the labor contract. The latter is characterized by the following two equations:

$$
\begin{aligned}
w_{j, t} h_{i, j, t} & =(1-\xi)\left[\alpha\left(\frac{P_{j, t}}{P_{t}}-\nu_{j, t}\right)\left(\frac{Y_{j, t}+F}{N_{j, t}}\right)+\omega \frac{V_{t}}{U_{t}}\right]+\xi \frac{\Gamma^{u}-\Gamma_{t}^{n}}{\lambda_{t}} \\
-\frac{\partial \Gamma_{t}^{n}}{\partial h_{j, t}} & =\alpha^{2}\left(\frac{P_{j, t}}{P_{t}}-\nu_{j, t}\right)\left(\frac{Y_{j, t}+F}{N_{j, t} h_{j, t}}\right) \lambda_{t}
\end{aligned}
$$

The worker's wage bill is a weighted average of the worker's contribution to output augmented by the average hiring costs for each unemployed worker, and the worker's outside opportunity. The last one refers to the utility gain of leisure. Equations (2) and (3) show that the mark-up's fluctuations on the goods market affect the dynamics of the wage bill and hours per worker: when the mark-up on the goods market rises, it decreases the marginal value of a job match for the firm, which leads to a decrease in the wage bill and hours per worker.

\section{Calibration}

The value that is added by including money supply shocks in a decentralized labor market search economy can be evaluated by the improvement of the model's fit. For this purpose, simulation experiments are conducted. We solve the intertemporal general equilibrium related to the monetary model with labor market search described above. Three versions of this model are simulated: 
(i) the model MI corresponds to this model without money supply disturbances and price adjustment costs, but with perfect competition on the goods markets i.e. $\gamma=\phi=0$ and $\epsilon_{g, t}=0 \forall t$; it differs from the model of Andolfatto [1996] only via the introduction of the money demand behavior.

(ii) the model M2 corresponds to the model M1 augmented by monopolistic competition and sticky prices on the goods market.

(iii) the model M3 corresponds to the model M2, augmented by money supply disturbances.

In order to compute the model's equilibrium, values must be assigned to structural parameters. Thus, we use the restrictions impose by the theory to set these values, given information on aggregate variables and external information from cross-sectional evidences.

Concerning the real part of the economy, our calibration is the same as the one retained by Andolfatto [1996]: the discount factor is set to $\beta=0.99$, the depreciation rate of capital to $\delta=0.025$, the elasticity of the production function with respect to capital to $1-\alpha=0.36^{11}$, the ratio of recruiting expenditures to $\frac{\omega V}{Y}=0.01$, the quarterly rate of transition from employment to nonemployment to $s=0.15$, the average employment ratio to $N=0.57$, the average fraction of time spent working to $h=1 / 3$, the average fraction of time that nonemployed households spend searching $e=(1 / 2) h$, the probability that a vacant position becomes a productive job to $\Theta=0.9$, the elasticity of the matching rate with respect to aggregate recruiting intensity, as the firm's bargaining power, respectively to $\psi=0.6$ and $\xi=0.6$, and the individual labor supply elasticity is set to $\eta^{-1}\left(\frac{1}{h}-1\right)=1$, which implies $\eta=2$. Finally, the technology parameter $A$ is chosen to normalize the level of output to unity and the values of $\gamma_{1}$ and $\Gamma_{u}$ are set in order to satisfy respectively the equation (3) and the equation (4) in appendix $A$, at steady-state.

Concerning our additional parameters, the mark-up on the goods market is equal to $10 \%$ as in Hairault and Portier [1993] and the index of increasing returns, $F$, is set in order to get zero pur profit at steady state. The elasticity of substitution between the consumption and real balances is small but significantly different from zero (Koenig [1990]): we set it to $\sigma=1 \%$. Then the value of $\gamma_{3}$ is set in order to satisfy the restriction imposed by the steady-state (derived from equation (1)). Our strategy to calibrate the

\footnotetext{
${ }^{11}$ As we assume zero pur profit the labor's share does not depend on the mark-up on
the goods market, at steady state.
} 
parameter of price adjustment costs is as follows: we choose a value of $\phi$ so that our artificial economy gets the observed standard deviation of real per-capita output. It implies $\phi=12$ and a ratio of price adjustment costs to output approximatively equal to $0.1 \%$. Then, equation (6) gives the value of $\gamma$. The monetary growth process is set as in Cooley and Hansen [1995]: $\sigma_{\epsilon_{g}}=0.0089, \rho_{g}=0.49$ and $\bar{g}=1.013 . \frac{M_{t}}{P_{t}}$ is set to $88 \%$ of the amount of non-durables consumption and services: this value is consistent with the estimation of the velocity of money and with the survey data reported by Cooley and Hansen [1995].

Table 1: Parameters values

\begin{tabular}{cccccccc}
\hline$A$ & $F$ & $\gamma$ & $\gamma_{1}$ & $\Gamma_{u}$ & $\gamma_{3}$ & $\rho_{A}$ & $\sigma_{A}$ \\
1.38 & 0.1 & 0.1 & 1.28 & 0.4 & $6.5 \times 10^{-8}$ & 0.935 & 0.0072 \\
\hline
\end{tabular}

Finally, as the mark-up on the goods market fluctuates, we choose to calibrate the stochastic process of the technological shock so that the model reproduces the Solow residual process estimated by Cooley and Prescott [1995].

\section{Results}

Andolfatto [1996] shows that the labor market search assumption implies a quantitatively important propagation mechanism. However, some disappointing results remain: (i) volatilities of hours per worker and labor's share are underestimated, (ii) the counter-cyclically of the labor's share is overestimated, and (iii) contemporaneous correlations of hours with productivity and the real wage are still close to one, whereas their empirical counterpart are negative. Thus, beyond the reproduction of the dynamics around the Phillips and Beveridge curves, the aim of this section is to show how fluctuations in the mark-up on the goods market and the occurrence of money supply shocks improve these previous results.

In this section, we propose to test the empirical relevance of the propagation mechanisms implied by money supply shocks. For this purpose, we first identify the specific propagation mechanisms related to money supply shocks, using the impulse response functions (IRF) of the model M3 to both technological and money supply shocks. Then, the second order moments generated by the simulations of the three versions of our model are compared. 


\subsection{Propagation Mechanisms on the Labor Market}

We successively examine the IRF of aggregate variables to technological and money supply shocks, in order to identify the specific propagation mechanisms related to the demand shocks (figures are reported in appendix B).

\subsubsection{IRF to a Technological Shock}

In our monetary model with labor market search, two discriminating features characterize dynamics of aggregate variables in response to a positive technological shock: (i) firms mainly adjust total hours via employment and (ii) labor's share decreases.

Following a positive highly serially correlated technological shock, the expected increase of the profitability of total hours is long-lasting. Although posting vacancies is costly, firms prefer to adjust the extensive margin of total hours rather than the intensive one. Thus, the magnitude of the adjustment of hours per worker is low, whereas employment gets a large increase (see figure 2). As the hiring is a time consuming process, it implies a hump-shape on the output (see figure 1).

In addition, since there are some price rigidities, the inflation rate decreases less than it would have done in the case of perfect competition on the goods market ${ }^{12}$; it implies an increase in the mark-up on this market. Given the specification of the labor contract, this phenomena smoothes hours per worker and the real wage, whereas it implies a large response of labor productivity to a technological shock. This accounts for the decrease in the labor's share (see figure 3).

\subsubsection{IRF to a Money Supply Shock}

Conversely, a positive money supply shock implies that (i) firms mainly adjust total hours via hours per worker, and (ii) labor's share increases.

Following a positive money supply shock, price rigidities induce a lower increases of the inflation than it would have done in the case of perfect competition on the goods market. Consequently, this leads to a fall in the mark-up on this market, which rises the profitability of total hours and capital for firms. So, vacancies and investment increase. However, since the autocorrelation of money supply shocks is very low, the expected growth of the profitability of total hours is short-lasting, and firms do not want to incur the cost of posting vacancies: they prefer to adjust total hours via

\footnotetext{
${ }^{12}$ The inflation rate decreases whereas employment increases.
} 
hours per worker (the intensive margin). Employment gets a small rise: this adjustment accounts for a negative correlation between inflation and unemployment. Hours per worker gets a large increase (see figure 5). Thus, output rises, but its dynamic displays low persistence. In addition, the decrease in the mark-up on the goods market and the rise of the outside opportunity (due to the increase of hours per worker), lead to a large increase in the real wage (see equation (2)). This dynamic of the real wage following a money supply shock is in accordance with the findings of Christiano et al. [1997]. Thus, productivity and the real wage display opposite dynamics (see figure $6)$, and the labor's share increases.

\subsection{Quantitative Evaluation}

Descriptive statistics obtained respectively for simulated data and US data are reported in tables 2 to 6 (appendix C). We use quarterly data for the sample period 1953:1-1990:3, as in Andolfatto [1996]. A complete description of these data is provided in appendix D. All series are transformed by taking logarithms and detrended using the Hodrick-Prescott filter. We then compute the second order moments of these series in order to have a synthetic view of US business cycle. A corresponding set of statistics is computed, using the simulated data generated by our model. All the simulated series are transformed in the same way as the per-capita US data.

\subsubsection{The Phillips and Beveridge Curves}

Tables 5 and 6 report statistics summarizing the cyclical relationship between unemployment, vacancies and inflation. These second order moments account for the dynamics around the Beveridge and Phillips curves.

US data display a strong negative correlation between vacancies and unemployment. This result provides an empirical justification to the Beveridge curve. It means that firms choose vacancies by expecting the profit gain in a job match at the next period. All our theoretical models account for this fact. Our results are not significantly different from those of Andolfatto. This means that the matching process assumption is sufficient to describe the dynamic of the frictional unemployment which is summarized by the fluctuations around the Beveridge curve.

The additional nominal dimension of our model can be tested by looking at the correlation between unemployment and inflation. It provides us a measure of the relative weight of technological and money supply shocks and allows to test if our theoretical framework is able to explain the observed 
interactions between real and nominal rigidities. US data show that there exists a negative correlation between inflation and unemployment. This underlines the inability of business cycle models, where technological shocks are the only source of economic fluctuations, to match this stylized fact: in particular, models M1 and M2 generate strong positive correlations between unemployment and inflation, as negative correlations between output and inflation. At the opposite, the fluctuations around the Phillips curve are well reproduced by the model M3 which incorporates money supply disturbances. Indeed, recall that following a positive money supply shock, inflation increases, but price rigidities implies a decrease in the mark-up on the goods market which leads to a rise in employment. Consequently, it accounts for the negative correlation between $f_{t}$ and $U_{t+1}{ }^{13}$. In addition, as shown in table 2 , the model M3 implies also a close reproduction of the correlation between output and inflation. Thus, real and nominal rigidities, introduced in our model, are sufficient to explain the observed interactions between prices and quantities. The variance decomposition of the forecast error of output and unemployment (see table 7) show that these results are due to the significant impact of money supply shocks on real aggregate variables, in short run dynamics. Moreover, the magnitude of this impact on the output is close to the one obtained by Gali [1992].

\subsubsection{Aggregate dynamics of hours per worker, employment, la- bor productivity and the real wage}

Firstly, we must notice that the introduction of a money demand behavior does not affect significantly the cyclical properties of labor market variables: the second order moments implied by our model M1 are close to those implied by the Andolfatto [1996] model.

In the US data, the great majority of hours variations is related to employment variations; the volatility of hours per worker explains a minor part of the standard deviation of total hours (see table 2). In the standard RBC economy, only hours per worker can be adjusted ${ }^{14}$. Search economies (models M1, M2 and M3) allow to distinguish between total hours dynamics, fluctuations in employment and fluctuations in hours per worker. In all these

\footnotetext{
${ }^{13}$ We must notice that, given our discretization choice of the flow model, this theoretical correlation is the relevant one.

${ }^{14}$ This strong implication can be reversed even in an $\mathrm{RBC}$ model. Indeed, the indivisibility of hours per worker assumed in the Hansen [1985] model implies that only the extensive margin fluctuates, since the number of hours per worker is fixed; however, this representation of labor market dynamics is clearly a caricature of the observed US labor market dynamics.
} 
models, the magnitude of changes in employment are greater than in those of hours per worker. However, the real economy proposed by Andolfatto [1996], as our models M1 and M2, underestimate the volatility of the hours per worker. The model M3 improves this result: since firms mainly adjust total hours via hours per worker following a money supply shock, this implies that the standard deviation of hours per worker is remarkably well reproduced. Consequently, the volatility of total hours is also higher, in accordance with US data. In this dimension, the model M3 displays that adding money supply shocks and nominal rigidities improve the promising results obtained by Andolfatto [1996].

The second point refers to the dynamic of the labor's share, which is an indication, (i) of the way that fluctuations of the real wage differs from those of labor productivity, and (ii) of the profit's share dynamic. Andolfatto's economy, as our model M1, underestimate the labor's share volatility and overestimates its counter-cyclically ${ }^{15}$. Then, adding the nominal dimension improves the ability of the model to match the data: following a positive money supply shock, the decrease of the mark-up on the goods market leads to an increase of the real wage, whereas labor productivity decreases. This implies that the labor's share is procyclical following a money supply shock. It explains why, relatively to Andolfatto [1996]'s model, our model model M3 displays a higher volatility and a lower counter-cyclically of the labor's share, which is in accordance with US stylized facts. Consequently, this result underlines the ability of our model to account for the fluctuations of the profit's share (defined in accordance with our model: $1-\frac{w h N}{Y}$.).

Table 2 also shows that in the US economy, the real wage is smoother than labor productivity. Another difference between the dynamics of these two time series is that the real wage displays a low relationship with contemporaneous output. In a search economy, real or with a nominal dimension, labor productivity and the real wage have theoretically different paths ${ }^{16}$. Our model model M3 allows a closer match with the second stylized fact: the model implies a lower value for the instantaneous correlation of productivity with output. Since productivity decreases instantaneously following a positive money supply shock, whereas output displays a low persistent increase, it contributes to the decrease of the correlation of the productivity with output. This mechanism accounts also for a lower correlation of productivity with total hours. However, our specific assumption is still disappointing with

\footnotetext{
${ }^{15}$ In a standard RBC model, labor productivity and the real wage share the same dynamics; it implies that the labor's share is constant over time.

${ }^{16}$ This is particularly true, in our monetary model with search on the labor market: following a money supply shock labor productivity decreases, whereas the real wage increases.
} 
respect to the dynamic of the real wage.

\section{Concluding Remarks}

This paper suggests that a monetary model with labor market search can account for the fluctuations around the Phillips and Beveridge curves. In addition, the propagation of money supply disturbances improves our understanding of several cyclical labor market properties: (i) volatilities of hours per worker and the labor's share, (ii) the counter-cyclically of the labor's share, and (iii) contemporaneous correlations of total hours and output with labor productivity are closer to the stylized facts in the model M3 than in the Andolfatto [1996] model. Nevertheless, some further research must be conducted to explain the real wage dynamic.

\section{References}

Andolfatto, D., Business Cycle and Labor Market Search, American Economic Review, 1996, 86, 112-132.

Christiano, L.S, M. Eichenbaum, and C.L. Evans, Sticky Price and Limited Participation Models of Money, European Economic Review, 1997, 41, 1201-1249.

Cogley, T. and J. Nason, Outputs Dynamics in Real Business Cycle Models, American Economic Review, 1995, 85, 492-511.

Cole, H. and R. Rogerson, Can the Mortensen-Pissarides Matching Model Match the Business Cycle Facts?, Working paper, Federal Reserve Bank of Minneapolis and University of Minnesota 1996.

Cooley, T. and E. Prescott, Economic Growth and Business Cycle, in T. Cooley, editor, Frontiers of Business Cycle Research, Princeton: Princeton University Press, 1995.

- and G. Hansen, Money and the Business Cycle, in T. Cooley, editor, Frontiers of Business Cycle Research, Princeton: Princeton University Press, 1995.

and __ The Role of Monetary Shocks in Equilibrium Business Cycle Theory: Three Examples, Working paper, UCLA 1997. 
Cooley, T.F. and V. Quadrini, A Model of The Phillips Curve Relation, working paper, University of Rochester, Duke University 1998.

Fève, P. and F. Langot, Unemployment and the Business Cycle in a Small Open Economy. G.M.M. Estimation and Testing on French Data., Journal of Economic Dynamics and Control, 1996, 20, 1609-1639.

Friedman, M., The Role of Monetary Policy, American Economic Review, 1968, 58 (1), 1-17.

Gali, J., How Well Does the IS-LM Fit Postwar Data, Quarterly Journal of Economics, 1992, 107 (2), 709-738.

Haan, W.J. Den, G. Ramey, and J. Watson, Job Destruction and Propagation of Shocks, Working paper 97-23, University of California, San Diego 1997.

Hairault, J.O. and F. Portier, Money, New-Keynesian Macroeconomics and the business Cycle, European Economic Review, 1993, (37), 1533-1568.

Hansen, G., Indivisible Labor and the Business Cycles, Journal of Monetary Economics, 1985, 16 (3), 309-327.

Ireland, P.N., A Small, Structural, Quarterly Model for Monetary Policy Evaluation, Canergie-Rochester Conference, 1997, pp. 85-108.

Koenig, E., Real Money Balances and the Timing of Consumption: An Empirical Investigation, Quarterly Journal of Economics, 1990, 105 (2), 399-425.

Kydland, F. and E. Prescott, Time to Build and Aggregate Fluctuations, Econometrica, Novembre 1982, 50 (6), 1345-1370.

Merz, M., Search in the Labor Market and Real Business Cycle, Journal of Monetary Economics, 1995, 36, 269-300.

Mortensen, D.T., The Cyclical Behavior of Job and Worker Flows, Journal of Economic Dynamics and Control, 1994, 18, 1121-1142.

Phelps, S. and . al., Microeconomic Foundation of Employment and Inflation Theory, New York: Norton, 1970.

Pissarides, C., Equilibrium Unemployment Theory, Basil Blackwell, 1990. 
Rotemberg, J., Sticky Prices in the United Sates, Journal of Political Economy, 1982, 90, 1187-2011.

and M. Woodford, Dynamic general equilibrium models with imperfectly competitive product markets, in T. Cooley, editor, Frontiers of Business Cycle Research, Princeton University Press, 1995.

\section{A The Firm's Decision Rules}

The Euler equations that govern the firm's intertemporal behavior of vacancies, investment and price are respectively given by:

$$
\begin{aligned}
\frac{\omega V_{t}}{H_{t}}= & \beta E_{t}\left[\frac { \lambda _ { t + 1 } } { \lambda _ { t } } \left\{\left(\frac{P_{j, t+1}}{P_{t+1}}-\nu_{j, t+1}\right) \alpha \frac{Y_{j, t+1}+F}{N_{j, t+1}}\right.\right. \\
& \left.\left.-w_{j, t+1} h_{j, t+1}+\frac{(1-s) \omega V_{t+1}}{H_{t+1}}\right\}\right] \\
1= & \beta E_{t}\left[\frac{\lambda_{t+1}}{\lambda_{t}}\left\{\left(\frac{P_{j, t+1}}{P_{t+1}}-\nu_{j, t+1}\right)(1-\alpha) \frac{Y_{j, t+1}+F}{K_{j, t+1}}+1-\delta\right\}\right] \\
Y_{j, t}= & \frac{1+\gamma}{\gamma} \nu_{j, t}\left(\frac{P_{j, t}}{P_{t}}\right)^{-\frac{1+\gamma}{\gamma}-1} Y_{t}+\phi \frac{P_{t}}{P_{j, t-1}}\left(\frac{P_{j, t}}{P_{j, t-1}}-1\right) \\
& -\beta E_{t}\left[\phi \frac{\lambda_{t+1}}{\lambda_{t}}\left(\frac{P_{j, t+1} P_{t}}{P_{j, t}^{2}}\right)\left(\frac{P_{j, t+1}}{P_{j, t}}-1\right)\right]
\end{aligned}
$$

\section{B Impulse Response Functions \\ B.1 IRF to a Technological Shock}


Figure 1:
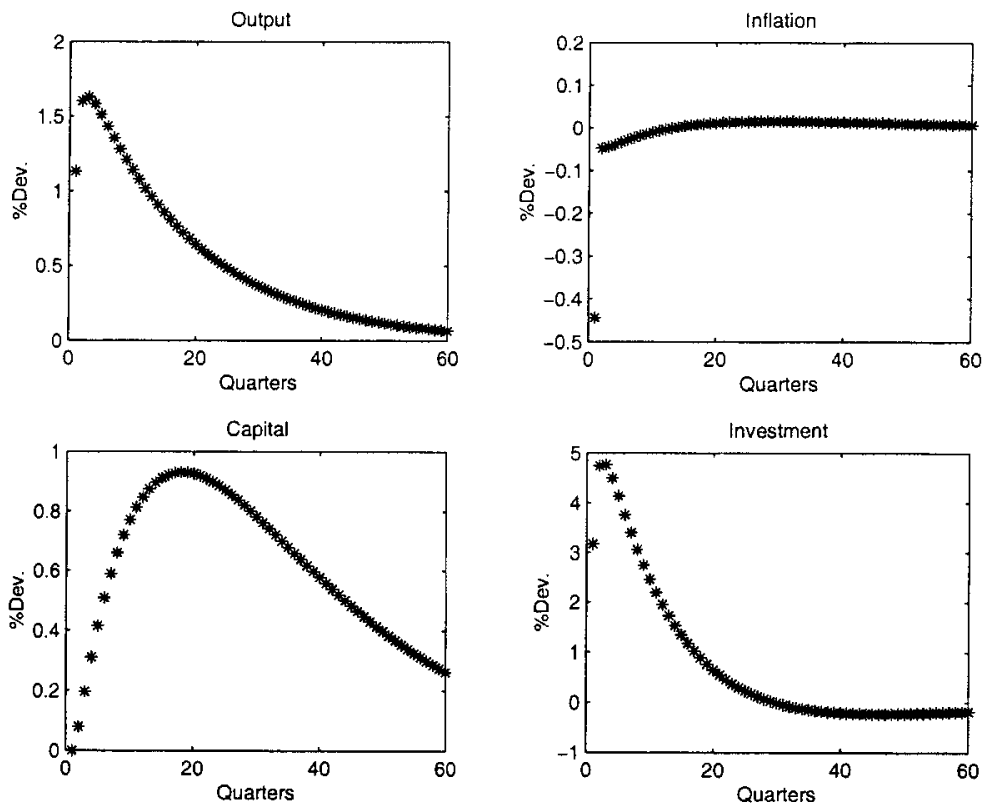

Figure 2:
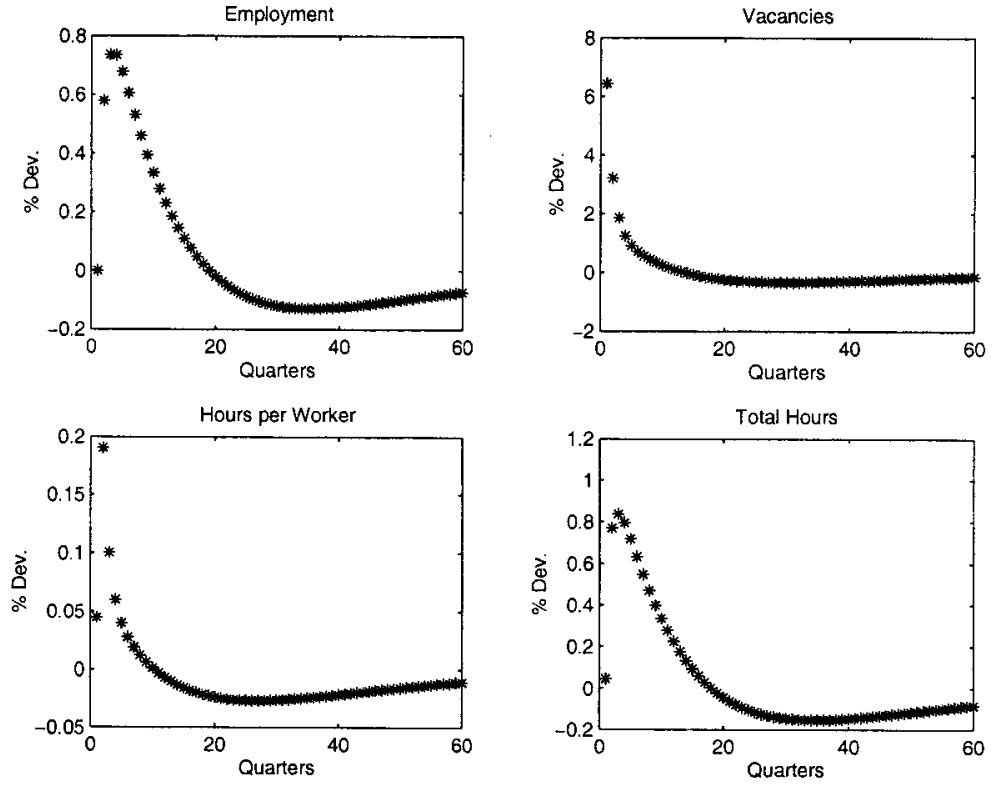
Figure 3:
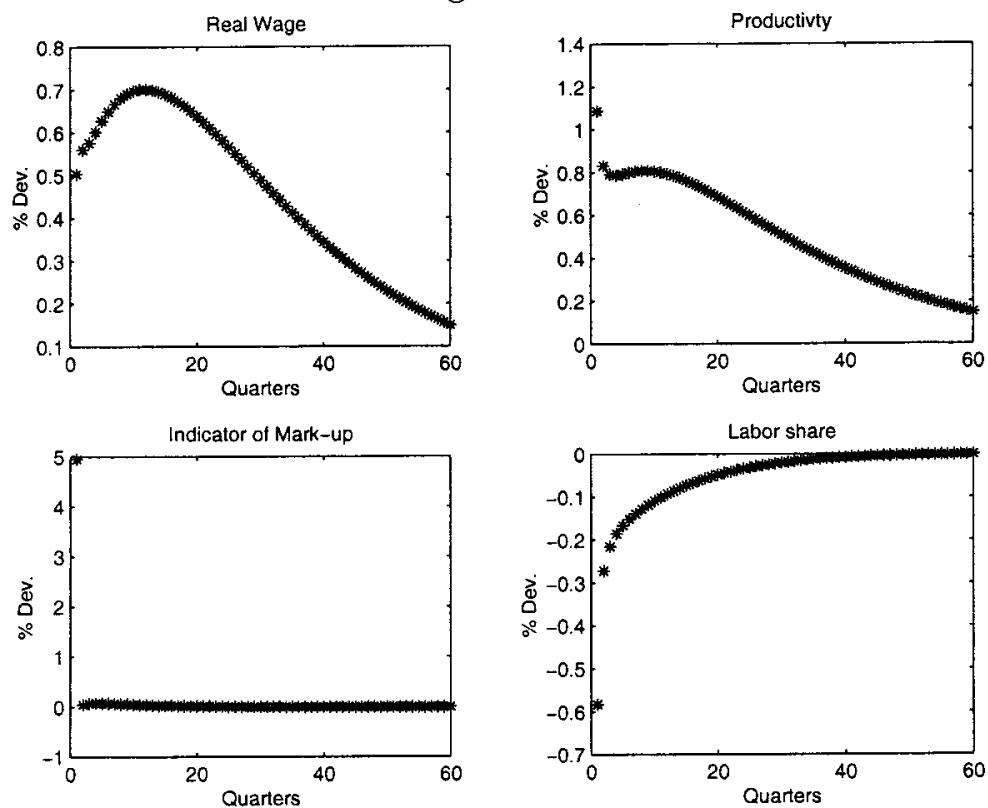

\section{B.2 IRF to a Money Supply Shock}


Figure 4:
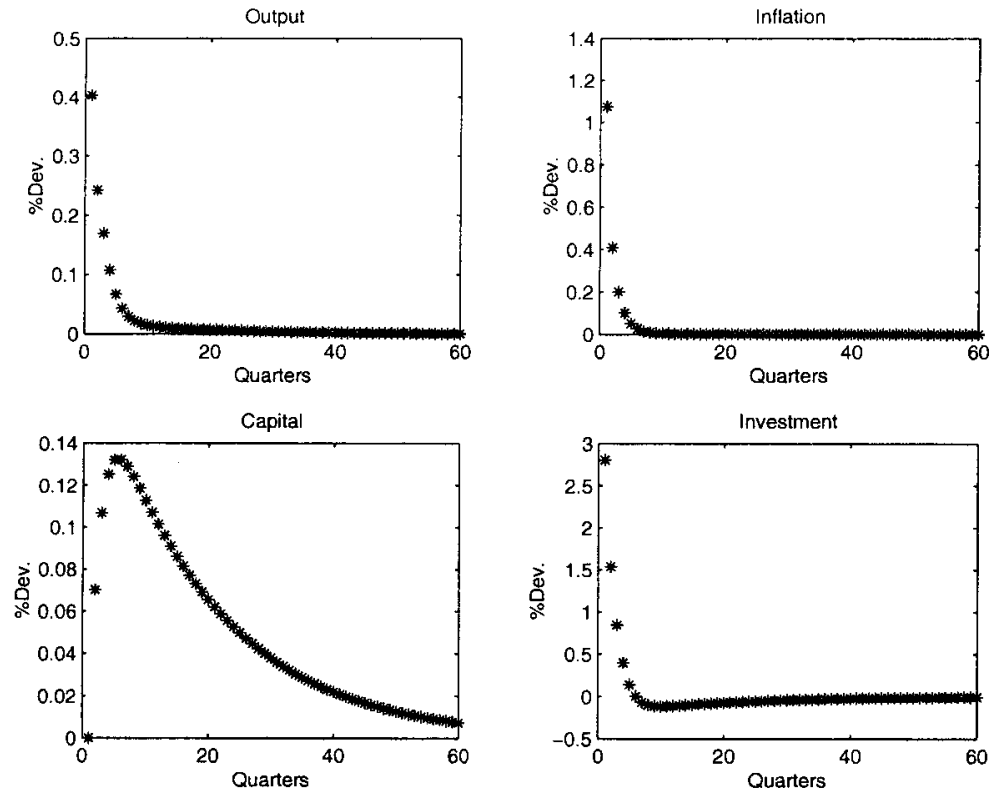

Figure 5:
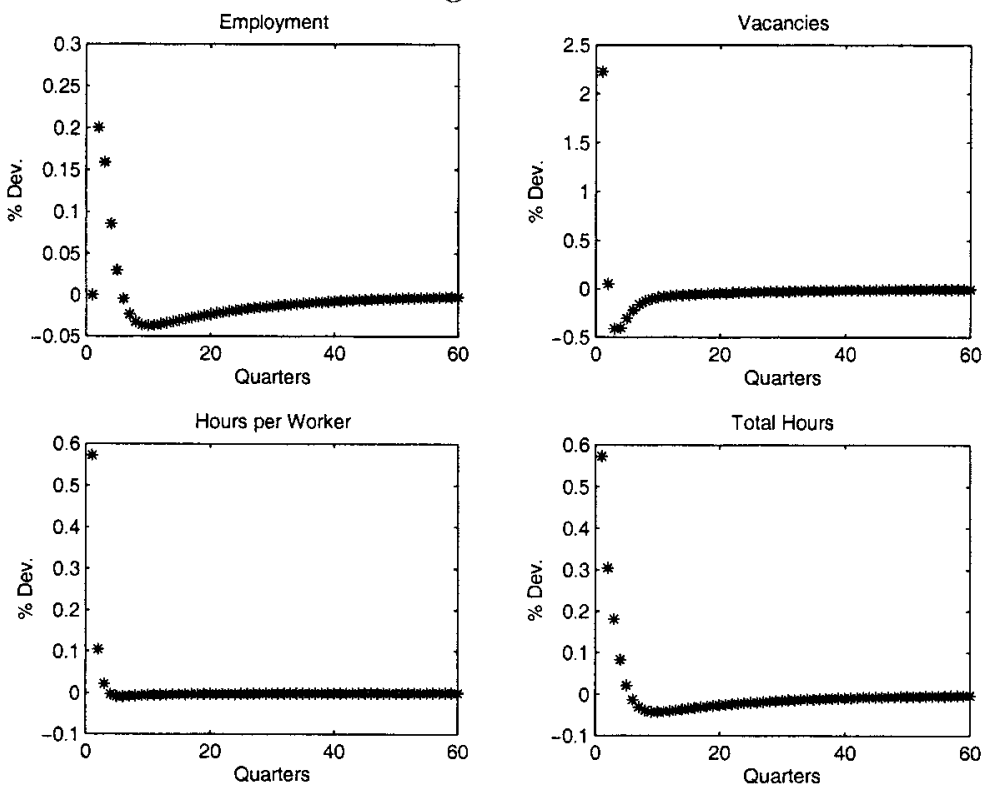
Figure 6:

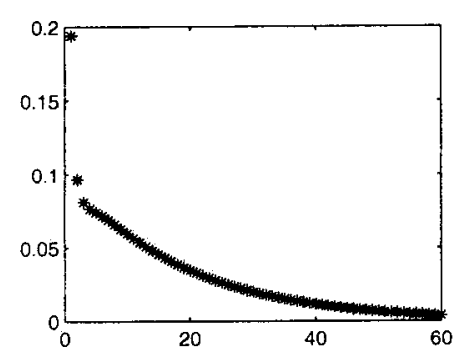

C Cyclical Properties 
Table 2: US and Artificial Economies Cyclical Properties (I)

\begin{tabular}{cccccccccccc}
\hline \hline & \multicolumn{2}{c}{ US } & \multicolumn{1}{c}{ Andolfatto } & \multicolumn{2}{c}{ M1 } & \multicolumn{2}{c}{ M2 } & \multicolumn{2}{c}{ M3 } \\
& $\sigma(y)=1.58$ & \multicolumn{2}{c}{$\sigma(y)=1.45$} & $\sigma(y)=1.48$ & $\sigma(y)=1.54$ & $\sigma(y)=1.58$ \\
$x$ & $(1)$ & $(2)$ & $(1)$ & $(2)$ & $(1)$ & $(2)$ & $(1)$ & $(2)$ & $(1)$ & $(2)$ \\
\hline$C$ & 0.56 & 0.74 & 0.32 & 0.91 & 0.31 & 0.90 & 0.32 & 0.90 & 0.55 & 0.40 \\
$I$ & 3.14 & 0.90 & 2.98 & 0.99 & 3.12 & 0.99 & 3.15 & 0.99 & 3.46 & 0.95 \\
& & & & & & & & & & \\
$N h$ & 0.93 & 0.78 & 0.59 & 0.96 & 0.56 & 0.96 & 0.55 & 0.90 & 0.64 & 0.85 \\
$N$ & 0.67 & 0.73 & 0.51 & 0.82 & 0.57 & 0.83 & 0.50 & 0.87 & 0.51 & 0.86 \\
$h$ & 0.34 & 0.66 & 0.22 & 0.66 & 0.20 & 0.57 & 0.09 & 0.74 & 0.33 & 0.38 \\
& & & & & & & & & & \\
$w h N / Y$ & 0.68 & -0.38 & 0.10 & -0.62 & 0.13 & -0.55 & 0.25 & -0.66 & 0.34 & -0.37 \\
$Y / N h$ & 0.64 & 0.43 & 0.46 & 0.94 & 0.44 & 0.91 & 0.55 & 0.90 & 0.56 & 0.80 \\
$w$ & 0.44 & 0.04 & 0.39 & 0.95 & 0.35 & 0.93 & 0.35 & 0.93 & 0.36 & 0.93 \\
& & & & & & & & & & \\
$f$ & 0.40 & 0.13 & - & - & 0.19 & -0.41 & 0.20 & -0.32 & 0.65 & 0.09 \\
\hline \hline
\end{tabular}

$\sigma(y):$ s-d in real per-capita output.

Column (1): $\sigma(x) / \sigma(y)$, Column (2): $\operatorname{corr}(x, y)$.

$f$ denotes the inflation. 
Table 3: Cross Correlations of Total Hours with Productivity

\begin{tabular}{lcccccccc}
\hline \hline$\tau$ & -3 & -2 & -1 & 0 & 1 & 2 & 3 \\
\hline US Economy & 0.43 & 0.31 & 0.10 & -0.22 & -0.25 & -0.27 & -0.31 \\
Andolfatto & 0.38 & 0.63 & 0.82 & 0.81 & 0.56 & 0.40 & 0.28 \\
M1 & 0.32 & 0.58 & 0.80 & 0.76 & 0.51 & 0.36 & 0.26 \\
M2 & 0.37 & 0.65 & 0.89 & 0.62 & 0.45 & 0.32 & 0.22 \\
M3 & 0.29 & 0.48 & 0.64 & 0.37 & 0.32 & 0.26 & 0.20 \\
\hline
\end{tabular}

Table 4: Cross Correlations of Total Hours with Real Wage

\begin{tabular}{lcccccccc}
\hline \hline$\tau$ & -3 & -2 & -1 & 0 & 1 & 2 & 3 \\
\hline US Economy & -0.1 & -0.01 & 0.01 & -0.13 & 0.10 & 0.19 & 0.18 \\
Andolfatto & 0.30 & 0.57 & 0.80 & 0.84 & 0.66 & 0.52 & 0.40 \\
M1 & 0.20 & 0.49 & 0.76 & 0.82 & 0.66 & 0.54 & 0.43 \\
M2 & 0.22 & 0.52 & 0.82 & 0.74 & 0.62 & 0.50 & 0.40 \\
M3 & 0.13 & 0.39 & 0.68 & 0.72 & 0.53 & 0.43 & 0.34 \\
\hline
\end{tabular}


Table 5: Cross Correlations of Unemployment with Vacancies

\begin{tabular}{lcccccccc}
\hline$\tau$ & -3 & -2 & -1 & 0 & 1 & 2 & 3 \\
\hline US Economy & -0.62 & -0.82 & -0.92 & -0.89 & -0.72 & -0.47 & -0.21 \\
Andolfatto & -0.65 & -0.73 & -0.65 & -0.19 & 0.05 & 0.17 & 0.24 \\
M1 & -0.59 & -0.69 & -0.65 & -0.14 & 0.08 & 0.18 & 0.22 \\
M2 & -0.59 & -0.69 & -0.63 & -0.14 & 0.08 & 0.18 & 0.22 \\
M3 & -0.45 & -0.66 & -0.64 & -0.10 & 0.10 & 0.18 & 0.20 \\
\hline
\end{tabular}

Table 6: Cross Correlations of Unemployment with Inflation

\begin{tabular}{lccccccc}
\hline \hline$\tau$ & -3 & -2 & -1 & 0 & 1 & 2 & 3 \\
\hline US Economy & -0.15 & -0.18 & -0.24 & -0.16 & -0.13 & -0.12 & -0.17 \\
M1 & 0.45 & 0.50 & 0.40 & -0.12 & -0.13 & -0.15 & -0.16 \\
M2 & 0.44 & 0.49 & 0.40 & -0.12 & -0.14 & -0.15 & -0.16 \\
M3 & 0.07 & -0.01 & -0.11 & -0.07 & -0.02 & -0.02 & -0.02 \\
\hline \hline
\end{tabular}

The statistics refer to the $\tau$ th lead of productivity if $\tau<0$, and to its $\tau$ th lag if $\tau>0$. 
Table 7: Variance Decomposition of the Forecast Error of Output and unemployment

\begin{tabular}{ccc}
\hline \hline \multicolumn{2}{c}{ Percentage of Variance Due to Money Supply Shock } \\
$\begin{array}{c}\text { Horizon } \\
\text { (Quarters) }\end{array}$ & Output & Unemployment \\
\hline 1 & 15.05 & 14.29 \\
2 & 7.41 & 9.31 \\
3 & 5.06 & 6.53 \\
4 & 3.86 & 5.04 \\
8 & 2.13 & 3.47 \\
12 & 1.64 & 3.41 \\
40 & 1.17 & 3.54 \\
\hline \hline
\end{tabular}

\section{Data}

The data used in this study are real aggregate data of the United States for the sample period 1954:1-1990:3; the source is Citicorp's citibase data bank.

Consumption $(C)=($ GCN82+GCS82+GGE 82$) /$ PO16

Investment $(I)=($ GCD82+GIF 82$) / \mathrm{PO} 16$

Output $(Y)=$ Consumption + Investment

Hours $(N h)=\left(\right.$ LHEM $^{*}$ LHCH $) /$ PO16

Employment $(N)=$ LHEM/PO16

Hours per worker $(h)=\mathrm{LHCH}$

Productivity $(Y / N h)=$ Output/Hours

Vacancies $(V)=$ LHELX $^{*}$ LHPAR $^{*}$ LHUR

Labor's share $(w h N / Y)=$ GAP/GDY/PO16/Output

Real wage $(w)=\mathrm{GAP} / \mathrm{GDY} / \mathrm{PO} 16 /$ Hours

Inflation $(f)=\operatorname{GDY} / \operatorname{GDY}(-1)$ 